\title{
Perspective Piece \\ Malaria Situation in the Peruvian Amazon during the COVID-19 Pandemic
}

\author{
Katherine Torres, ${ }^{1,2}$ Freddy Alava, ${ }^{3,4}$ Verónica Soto-Calle, ${ }^{5}$ Alejandro Llanos-Cuentas, ${ }^{2}$ Hugo Rodriguez, ${ }^{6}$ Lidia Llacsahuanga, \\ Dionicia Gamboa, ${ }^{1,2,7 *}$ and Joseph Vinetz ${ }^{1,3,8 *}$ \\ ${ }^{1}$ Laboratorios de Investigacion y Desarrollo, Facultad de Ciencias y Filosofia, Universidad Peruana Cayetano Heredia, Lima, Peru; ${ }^{2}$ Instituto de \\ Medicina Tropical Alexander von Humboldt, Universidad Peruana Cayetano Heredia, Lima, Peru; ${ }^{3}$ Laboratorio Amazonía-ICEMR y Enfermedades \\ Emergentes Sede Iquitos, Universidad Peruana Cayetano Heredia, Lima, Peru; ${ }^{4}$ Dirección Regional de Salud Loreto (DIRESA), Iquitos, \\ Perú; ${ }^{5}$ Dirección de Prevención y Control de Enfermedades Metaxénicas y Zoonosis, Ministerio de Salud, Lima, Perú; ${ }^{6}$ Universidad Nacional \\ de la Amazonía Peruana, Iquitos, Perú; ${ }^{7}$ Departamento de Ciencias Celulares y Moleculares, Facultad de Ciencias y Filosofia, Universidad \\ Peruana Cayetano Heredia, Lima, Peru; ${ }^{8}$ Section of Infectious Diseases, Department of Internal Medicine, Yale School of Medicine, \\ New Haven, Connecticut
}

Abstract. The Peruvian Ministry of Health reports a near absence of malaria cases in the Amazon region during the COVID-19 pandemic. However, the rapid increase in SARS-CoV-2 infections has overwhelmed the Peruvian health system, leading to national panic and closure of public medical facilities, casting doubt on how accurately malaria cases' numbers reflect reality. In the Amazon region of Loreto, where malaria cases are concentrated, COVID-19 has led to nearcomplete closure of the primary healthcare system, and diagnosis and treatment of acute febrile illnesses, including malaria, has plummeted. Here, we describe the potential association of COVID-19 with a markedly reduced number of reported malaria cases due to the reduced control activities carried out by the Peruvian Malaria Zero Program, which could lead to malaria resurgence and an excess of morbidity and mortality.

Malaria continues to be a high-priority public health concern in tropical and subtropical regions of the world, ${ }^{1}$ including the Peruvian Amazon, which is also endemic for several other acute febrile diseases such as dengue and leptospirosis. In Peru, malaria is concentrated primarily in the Loreto department, where transmission is maintained in rural and periurban communities.

In 2017, the Peruvian government brought a formal malaria elimination plan into law, the Malaria Zero Program (MZP), that takes a community-level approach to control malaria with the goal of elimination by 2030 . The MZP has three complementary and partially overlapping phases: 1) the control phase, testing and treating, which focuses on the elimination of symptomatic infections and has a duration of 3 years; 2 ) a firstphase (elimination phase), the goal of which is to eliminate malaria parasites from individuals at a regional level by targeting asymptomatic and low-parasite-density infections (in addition to symptomatic infections) for an extended span of 10 years; and 3) a final elimination phase, to identify and ameliorate residual malaria transmission foci, including reintroductions which is expected to last 15 years. ${ }^{2,3}$ The MZP is currently in the first (control) phase prioritized in the high endemicity region of Loreto. Since 2018 , the number of malaria cases has decreased significantly (Figure 1), a reduction of $50 \%$ from 2017 to 2019 . This reduction has been attributed to work carried out in Loreto, such as test-and-treat strategies, provision of free antimalarials under control of the Ministry of Health $(\mathrm{MoH})$, and larviciding and pyrethroid spraying. ${ }^{4}$

Malaria control activities in Peru take place primarily in areas with a high number of indigenous communities which are most

\footnotetext{
*Address correspondence to Dionicia Gamboa, Department of Cellular \& Molecular Sciences, Faculty of Science and Philosophy, Institute of Tropical Medicine Alexander von Humboldt, Universidad Peruana Cayetano Heredia, Av. Honorio Delgado 430, Lima 31, Peru, E-mail: dionicia.gamboa@upch.pe or Joseph Vinetz, Yale School of Medicine, 25 York St., Winchester 403D, New Haven, CT 06520-8022, E-mail: joseph.vinetz@yale.edu.
}

affected by malaria. Activities focus on active case detection and include the delivery of malaria rapid diagnostic tests and antimalarial drugs to trained health promoters, who are key to diagnosing and treating uncomplicated malaria cases in their communities. Another important malaria control activity in the Loreto region is based on the use of insecticide-impregnated mosquito nets for vector control. Community health promoters also conduct educational activities in communities, another part of malaria control programs. All of these activities are routinely carried out by each institution that provides health services in malaria-endemic areas. ${ }^{2,3,5}$ These activities are strengthened by the MZP, which has an assigned budget for malaria control in areas of very high and high risk of malaria transmission. All of these organized activities require inperson work and contact, which make them vulnerable to interruptions by external events such as COVID-19.

The health system in the Loreto region is structured as health networks (Redes) and, within them, micro-networks (MicroRedes), where each MicroRed has a number of health posts as the unit providing basic health care. Each health post is required to report the number of malaria cases every week to the Directorate of Health of Loreto.

When COVID-19 started to spread throughout Peru, the Peruvian government established strict quarantine measures and a nationwide lockdown in March 2020. Despite the relatively quick response, the pandemic continued to spread, hitting the Loreto region particularly hard. In the face of the current obvious urgency of the COVID-19 pandemic impacting a region with many other acute febrile illnesses, we aimed to gain insight about possible associations of the pandemic with the malaria situation in the Loreto region of the Peruvian Amazon.

During the first months of lockdown in Peru, the rapid increase in SARS-CoV-2 infections destabilized the Peruvian health system in manifold ways, especially in the capital of the Loreto region, lquitos. The urgency and rapid increase in COVID-19 cases in lquitos (Table 1), ${ }^{6}$ the lack of evidence-based clinical protocols, the lack of personal protective equipment (PPE), the lack of oxygen, and, in some way, frank panic at 


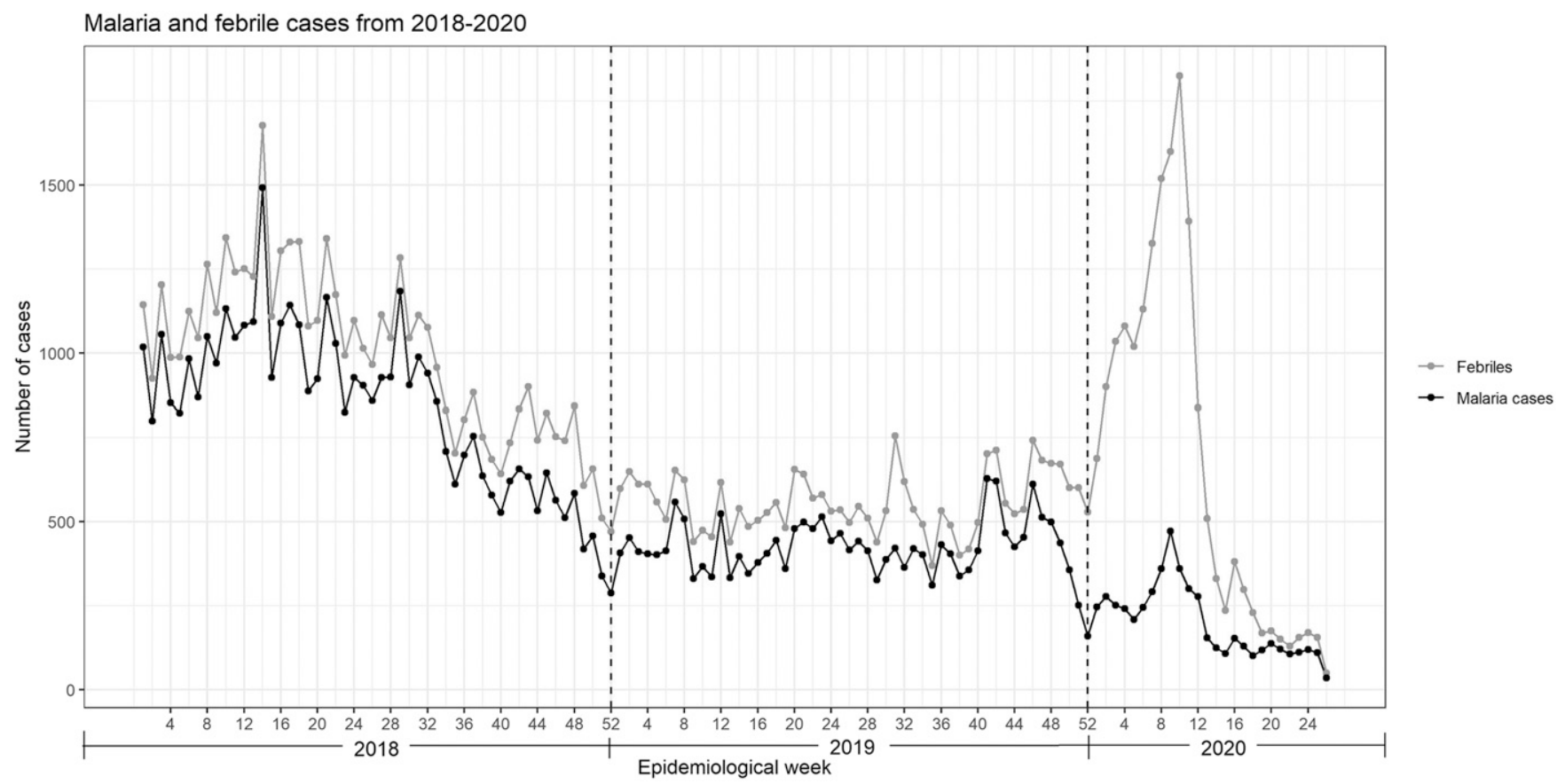

FIGURE 1. Malaria and febrile cases from 2018 to 2020 in the Loreto department of Peru. Source: Centro de Prevención y Control de Enfermedades-CPC de la Dirección Regional de Salud (DIRESA) de Loreto-MINSA. Data were extracted directly from NOTIV (data server from CPC-DIRESA in lquitos). Updated at epidemiological week 27, 2020. COVID-19 febrile cases are not included. Cases reported in the first 3 months of the year; after that, the number decreased significantly. Dengue outbreak from December 2019 to March 2020.

all hospitals throughout the country have exacerbated the public health crisis. This crisis was prominent at all hospitals in lquitos-which became dedicated COVID-19 hospitalsbecause healthcare workers lacked PPE, leading to many becoming ill from COVID-19, and some even dying. Hence, $\mathrm{MoH}$-supported facilities (health posts and hospitals) have closed for all clinical activities, except for COVID-19. These closures have contributed to delays in reporting malaria testing and confirmed cases in the entire region. On the other hand, people at home were also affected in diverse ways, many seemed to be dominated by fear, especially of attending health facilities. All of this has limited the collecting of key data, which hampers the determination of whether COVID-19 may have negative effects on national programs and research after 4 months of lockdown, and after that critical situation in lquitos.

At first sight, available data and observations seem to be limited by the availability of routine surveillance and basic implementation strategies in Loreto communities, which are usually carried out as part of regular activities of the $\mathrm{MoH}$ and supplemented by MZP and funded research projects. Regular interventions carried out by the MZP plummeted from the second half of April, when COVID-19 cases began their exponential increase in Loreto. Other malaria control activities, such as vector control, active detection, and community education, were postponed because of COVID-19, although from February 10 to February 28, the intra-household recycling activities with residual insecticide were reported for 656 houses in communities around the lquitos-Nauta road between the 15th and the 23rd km, protecting 1,815 people. According to MZP preliminary reports, the number of malariaspecific interventions and activities to date in 2020 has dropped by at least $60 \%$ compared with the same period in 2019. This situation may well continue until regional authorities organize the new way to do routine public health interventions under the COVID-19 situation. In addition, from 414 health posts, only $80 \%$ have been able to comply with the weekly notification in recent reporting periods, likely because of the COVID-19 situation. Thus, the health post malaria notification rate decreased to $62 \%$ during the pandemic lockdown. Nevertheless, recently, the malaria regional database has experienced some variability in the quality of information provided. Importantly, malaria is likely to resurge in the region in the absence of malaria diagnosis and treatment, leading to increased mortality and morbidity.

The apparent decline observed on the number of malaria cases since the pandemic started is remarkable. The reduction from February to March was 20\%; from March to April, 44\%; from April to May 21, 88\%; and from May to June 21, $99 \%$, ultimately reaching as few as 35 malaria cases in the last week of June. These reductions are striking for the region's known high transmission season (January-May). Moreover, the decrease in cases in Loreto after the outbreak was not only reported for malaria but also for dengue and leptospirosisother major causes of acute undifferentiated fever-the highest number of cases reported before the pandemic (Table 2).

The precise reasons why this COVID-19 situation may be associated with problems with malaria control cannot be fully determined at this time. Several factors likely contribute to an apparent decrease in cases. In addition to administrative shutdown, it is likely that people are not going to health facilities to get diagnosed (in case they do not have a health promoter in their communities) because the health centers are closed, or because of the convenience of feeling safe taking just an antipyretic at home and avoiding the risk of getting COVID-19. Furthermore, quarantine has compelled people to stay at home and limited their access to public transportation. 
TABLE 1

COVID-19 cases in Loreto region, Peru

\begin{tabular}{|c|c|c|c|c|c|c|}
\hline Province & District & Population & Confirmed cases & Suspected cases & Annual incidence rate $\times 10,000 \mathrm{Hab}^{*}$ & Deaths \\
\hline \multirow[t]{11}{*}{ Maynas } & Napo & 17,043 & 553 & 1,025 & 925.89 & 3 \\
\hline & Indiana & 11,830 & 162 & 89 & 212.17 & 20 \\
\hline & Iquitos & 157,591 & 1,721 & 1,215 & 186.31 & 724 \\
\hline & Punchana & 95,426 & 736 & 412 & 120.30 & 278 \\
\hline & Mazan & 14,424 & 85 & 31 & 80.42 & 4 \\
\hline & Belen & 79,260 & 338 & 242 & 73.18 & 175 \\
\hline & San Juan & 161,997 & 612 & 432 & 64.45 & 327 \\
\hline & Fernando Lores & 21,173 & 96 & 6 & 48.17 & 5 \\
\hline & Alto Nanay & 2,912 & 9 & 0 & 30.91 & 0 \\
\hline & Las Amazonas & 10,345 & 14 & 6 & 19.33 & 2 \\
\hline & Torres Causana & 5,388 & 0 & 2 & 3.71 & 1 \\
\hline \multirow[t]{4}{*}{ Alto Amazonas } & Yurimaguas & 75,576 & 844 & 246 & 144.23 & 64 \\
\hline & Teniente Cesar Lopez & 6,889 & 10 & 6 & 23.23 & - \\
\hline & Lagunas & 14,976 & 25 & 3 & 18.70 & - \\
\hline & Balsa Puerto & 18,244 & 7 & 3 & 5.48 & - \\
\hline \multirow[t]{5}{*}{ Datem del Marañon } & Barranca & 14,239 & 236 & 219 & 319.54 & - \\
\hline & Pastaza & 6,655 & 4 & 14 & 27.05 & - \\
\hline & Manseriche & 10,854 & 5 & 12 & 15.66 & - \\
\hline & Andoas & 12,936 & 0 & 3 & 2.32 & - \\
\hline & Cahuapanas & 8,719 & 0 & 2 & 2.29 & - \\
\hline \multirow[t]{5}{*}{ Loreto } & Nauta & 31,500 & 522 & 95 & 195.87 & 28 \\
\hline & Trompeteros & 11,247 & 107 & 3 & 97.80 & 7 \\
\hline & Tigre & 8,811 & 76 & 0 & 86.26 & - \\
\hline & Parinari & 7,596 & 40 & 3 & 56.61 & - \\
\hline & Urarinas & 15,399 & 10 & 1 & 7.14 & - \\
\hline Putumayo & Putumayo & 4,418 & 44 & 145 & 427.80 & 1 \\
\hline \multirow[t]{4}{*}{ Ramon Castilla } & Ramon Castilla & 25,275 & 601 & 8 & 240.95 & 26 \\
\hline & Yavari & 16,367 & 175 & 54 & 139.92 & 10 \\
\hline & Pebas & 17,859 & 72 & 55 & 71.11 & 4 \\
\hline & San Pablo & 16,821 & 64 & 0 & 38.05 & 8 \\
\hline \multirow[t]{8}{*}{ Requena } & Jenaro Herrera & 5,888 & 11 & 32 & 73.03 & 4 \\
\hline & Requena & 31,574 & 112 & 94 & 65.24 & 28 \\
\hline & Yaquerana & 3,124 & 9 & 0 & 28.81 & - \\
\hline & Puinahua & 6,289 & 11 & 1 & 19.08 & - \\
\hline & Maquia & 8,760 & 10 & 1 & 12.56 & 5 \\
\hline & Emilio San Martin & 7,830 & 2 & 4 & 7.66 & 4 \\
\hline & Capelo & 4,655 & 0 & 2 & 4.30 & 1 \\
\hline & Sapuena & 5,151 & 0 & 2 & 3.88 & 2 \\
\hline \multirow[t]{6}{*}{ Ucayali } & Contamana & 28,552 & 363 & 16 & 132.74 & 27 \\
\hline & Sarayacu & 17,343 & 62 & 1 & 36.33 & 5 \\
\hline & Padre Marquez & 7,947 & 21 & 0 & 26.43 & - \\
\hline & Vargas Guerra & 9,349 & 24 & 0 & 25.67 & 4 \\
\hline & Inahuaya & 2,782 & 4 & 0 & 14.38 & 1 \\
\hline & Pampa Hermosa & 11,124 & 2 & 1 & 2.70 & - \\
\hline
\end{tabular}

Centro de Prevención y Control de Enfermedades-CPC de la Dirección Regional de Salud de Loreto-MINSA. Updated at epidemiological week 26, 2020. Cases are considered since the onset of symptoms.

Research projects have also been affected at many institutions after the government declared the lockdown. Universities and research institutions had to completely suspend all laboratory and fieldwork activities. Consequently, research studies on diseases other than COVID-19 were paused. Closing laboratories and stopping research studies challenge the collaborative relationship between government and academia, so this situation could be a setback on the way to eliminate malaria. This situation is particularly worrisome because previous attempts to eliminate malaria in the region suggest that without focused control, a rapid bounce back effect can take place even after years of efforts. ${ }^{5}$ However, the full association of COVID-19 with this unprecedented situation of malaria control has yet to be determined.

TABLE 2

Malaria, dengue, and leptospirosis cases from 2018 to 2020

\begin{tabular}{|c|c|c|c|c|}
\hline & & \multicolumn{3}{|c|}{ Years } \\
\hline & & 2018 & 2019 & 2020 \\
\hline Number of febrile cases & & 51,945 & 29,013 & $17,493^{*}$ \\
\hline \multirow[t]{2}{*}{ Number of cases of malaria } & Plasmodium falciparum & 9,340 & 3,891 & $851 \dagger$ \\
\hline & Plasmodium vivax & 34,198 & 18,034 & $4,310 \dagger$ \\
\hline Number of cases of dengue & & 2,177 & 2,522 & $6,882 \ddagger$ \\
\hline Number of cases of leptospirosis & & 1,020 & 3,032 & $5,422 \dagger$ \\
\hline
\end{tabular}

Centro de Prevención y Control de Enfermedades-CPC de la Dirección Regional de Salud de Loreto-MINSA. Updated at epidemiological week 27, 2020. ${ }^{*}$ COVID-19 febrile cases are not included.

† Cases reported in the first 3 months of the year; after that, the number decreased significantly.

$\ddagger$ Dengue outbreak from December 2019 to March 2020. 


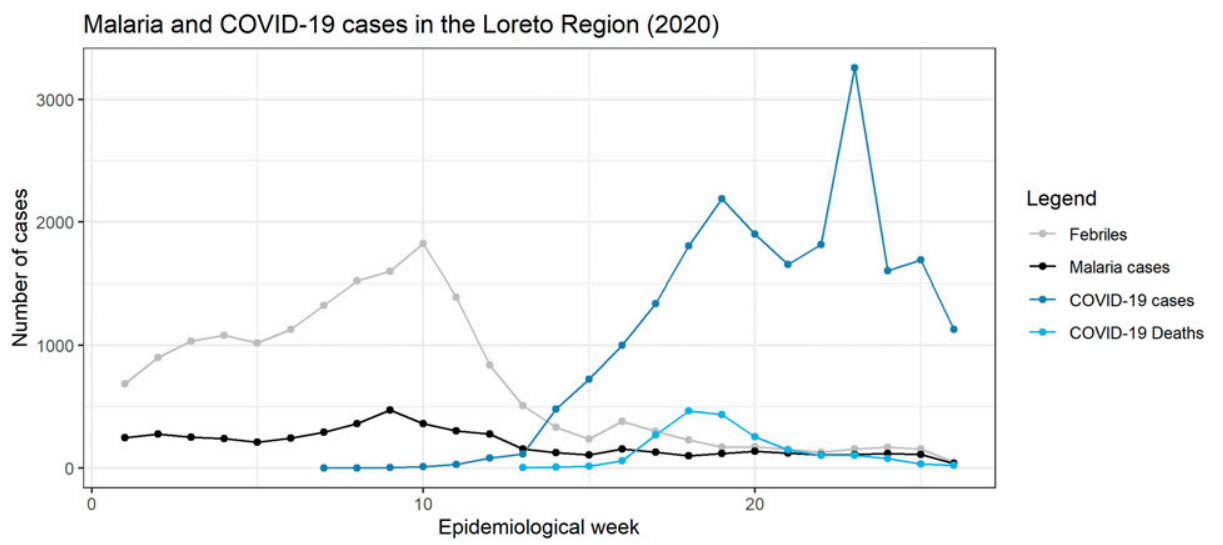

FIGURE 2. Malaria and COVID-19 cases in the Loreto region (2020). Source: Centro de Prevención y Control de Enfermedades-CPC de la Dirección Regional de Salud de Loreto-MINSA.

Not only will this pandemic challenge our advances in malaria control in the Loreto region of Peru but it will also affect the way we conduct research and interventions from now on. Because these activities cannot be indefinitely halted, they must be restarted following appropriate biosafety measures. New biosecurity strategies should be implemented, specifically the use of PPEs to protect us from the hazards of field and laboratory work, especially when we have to take samples, because of the high rate of COVID-19 infections in this area.

In lquitos, COVID-19 cases (symptomatic and asymptomatic) are being controlled (Figure 2), but expansion remains of high concern, especially after the suspension of the lockdown in Peru, which obligates the $\mathrm{MoH}$ to strengthen the strategies to control not only COVID-19 but also other endemic diseases in the Loreto region.

The COVID-19 pandemic is likely to have direct, measurable impacts on patients with endemic tropical and neglected infectious diseases and on related research. Here, we have described an apparent associate of COVID-19 with reduction in malaria control activities as carried out by the Peruvian MZP. We now confront the challenge of delivering malaria-related health care in remote areas where COVID-19 cases increase, especially affecting endangered indigenous communities. National and regional health systems remain challenged to provide adequate quality health care for those vulnerable, affected populations. The effect of COVID-19 on malaria resurgence and excess morbidity and mortality due to malaria can only be determined by prospective surveillance; however, this may be accomplished.

Received July 21, 2020. Accepted for publication August 27, 2020.

Published online September 3, 2020.

Acknowledgments: This work was supported by U.S. Public Health Service grants from the National Institutes of Health, U19AI089681, "Amazonian Center of Excellence in Malaria Research, and D43TW007120, "Translational Research Development for Endemic
Infectious Diseases of Amazonia." Publication charges for this article were waived due to the ongoing pandemic of COVID-19.

Authors' addresses: Katherine Torres and Alejandro Llanos-Cuentas, Instituto de Medicina Tropical Alexander von Humboldt, Universidad Peruana Cayetano Heredia, Lima, Peru, E-mails: kathjess2000@ yahoo.com and alejandro.llanos.c@upch.pe. Freddy Alava, Laboratorio Amazonía-ICEMR y Enfermedades Emergentes sede lquitos, Universidad Peruana Cayetano Heredia, Lima, Peru, E-mail: ffalare@ hotmail.com. Verónica Soto-Calle, Dirección de Prevención y Control de Enfermedades Metaxénicas y Zoonosis, Ministerio de Salud, Lima, Perú, E-mail: veronicasotocalle@gmail.com. Hugo Rodriguez, Dirección Regional de Salud Loreto, Ministerio de Salud, Iquitos, Perú, E-mail: hmrodriguezf@hotmail.com. Lidia Llacsahuanga and Dionicia Gamboa, Ciencias Celulares y Moleculares, Universidad Peruana Cayetano Heredia, Lima, Peru, E-mails: lidia.llacsahuanga@upch.pe and dioni gamboa@yahoo.com. Joseph Vinetz, Section of Infectious Diseases, Department of Internal Medicine, Yale School of Medicine, New Haven, CT, E-mail: dionicia.gamboa@upch.pe.

This is an open-access article distributed under the terms of the Creative Commons Attribution (CC-BY) License, which permits unrestricted use, distribution, and reproduction in any medium, provided the original author and source are credited.

\section{REFERENCES}

1. WHO, 2019. World Malaria Report 2019. Geneva, Switzerland: World Health Organization.

2. Ministerio de Salud, 2017. Resolución Ministerial N ${ }^{\circ}$ 244-2017-Minsa. Available at: https://www.gob.pe/institucion/minsa/normaslegales/189846-244-2017-minsa. Accessed August 26, 2020.

3. Ministerio de Salud, 2017. Marco para la Eliminación de la Malaria. Available at: http://bvs.minsa.gob.pe/local/MINSA/4253.pdf. Accessed August 26, 2020.

4. Ministerio de Salud, 2019. Bajan en más del 50\% los Casos de Malaria en el Perú. Available at: https://www.gob.pe/institucion/ minsa/noticias/27993-bajan-en-mas-del-50-los-casos-de-malariaen-el-peru. Accessed August 26, 2020.

5. Rosas-Aguirre A et al., 2016. Epidemiology of Plasmodium vivax malaria in Peru. Am J Trop Med Hyg 95: 133-144.

6. Ministerio de Salud, 2020. Situacion Actual "COVID-19" al 21 de Junio 2020. Available at: https://www.dge.gob.pe/portal/docs/tools/ coronavirus/coronavirus210620.pdf. Accessed August 26, 2020. 